\title{
COMBINING ABILITIES OF GRAIN YIELD AND YIELD RELATED TRAITS IN RELATION TO DROUGHT TOLERANCE IN TEMPERATE MAIZE BREEDING
}

\author{
Sekip ERDAL ${ }^{* 1}$, Mehmet PAMUKCU ${ }^{1}$, Ahmet OZTURK ${ }^{1}$, Koksal AYDINSAKIR ${ }^{1}$, Suleyman SOYLU ${ }^{2}$ \\ ${ }^{1}$ Bati Akdeniz Agricultural Research Institute, Antalya, TURKEY \\ ${ }^{2}$ Selcuk University, Faculty of Agriculture, Department of Field Crops, Konya, TURKEY \\ *Corresponding author: sekip.erdal@gthb.gov.tr
}

Received: 19.06.2015

\begin{abstract}
Temperate maize growing regions are increasingly prone to drought stress which is emerging as a primary constraint to maize productivity. Introgression of tropical sources of drought tolerance into temperate maize breeding may contribute to improving the drought tolerance of the relatively narrow temperate germplasm base that is currently in use. In the present study, seven tropical drought tolerant inbred lines and two welladapted commercial temperate inbred lines were crossed in a half-diallel design. The 9 parents, 36 diallel hybrids and 2 commercial checks were tested in well-watered and managed water stressed conditions in Antalya, Turkey in 2013 and 2014. Significant differences were detected between genotypes for number of days to anthesis, anthesis-silking interval, plant height, thousand kernel weight, number of ears per plant, number of kernels per ear and grain yield. Tropical inbreds G1 and G5 were comparable to the adapted temperate commercial inbreds in terms of general combining ability. Specific combining ability analysis revealed that tropical $x$ temperate hybrids had higher values compared to tropical $x$ tropical hybrids. Yield potential of hybrid G5 x G9 in particular, a promising tropical x temperate hybrid, was significantly higher under both well watered and drought conditions. Our results suggest that tropical drought tolerant germplasm is likely to have high utility in temperate maize breeding programs.
\end{abstract}

Key Words: maize breeding, combining ability, germplasm, water stress

\section{INTRODUCTION}

Maize (Zea mays L.) is a highly water-dependent crop and drought can cause considerable yield reductions throughout the growing cycle and especially during reproductive stage. Global warming, irregular rainfall and reduction of current water resources will adversely affect maize production in the future.

One of the most effective and practical strategies to mitigate drought risks to maize production is the development of varieties that have better tolerance to drought stress (Banziger et al. 2000; Ashraf et al. 2010).

In tropical maize, several initiatives have been undertaken over the years to improve drought tolerance in breeding programs. The International Maize and Wheat Improvement Center (CIMMYT) began improving tropical maize germplasm for drought stress through recurrent selection and direct evaluation under managed stress environments in the 1970s. (Fischer et al. 1989; Bolanos and Edmeades, 1993; Byrne et al. 1995; Edmeades et al. 1999). Edmeades et al. (1996) demonstrated that germplasm developed from drought tolerant source populations performed significantly better under drought stress compared to conventional populations. CIMMYT derived several inbreds from these drought tolerant source populations and has released hybrids that have good yield potential in the tropics (Beck et al. 1996). In temperate maize growing regions of the world, genetically modified approaches have been pursued in parallel to conventional breeding to improve drought tolerance, particularly in the US Corn Belt (Cooper et al. 2014). Improved phenotyping and molecular methods have also been used to develop drought tolerant temperate maize hybrids (Messina et al. 2009).

As a temperate zone country, Turkey produces about 5.9 million tones of maize per year and it is cultivated in approximately 0.66 million hectares (FAOSTAT, 2014). Maize is used primarily for livestock in Turkey and ranks third to wheat and barley in land under cereal cultivation. Maize is a summer season crop in Turkey and therefore rainfall has to be supplemented by irrigation in most growing regions (İlker et al. 2009). However, the frequency of drought is increasing throughout maize growing regions in Turkey, while the amount of water available for irrigation is reducing due to competition for 
other crops and land uses. In order to stabilize maize production in Turkey, there is need to develop maize hybrids with drought tolerance.

Since the advent of maize hybrid production and recycling of elite inbreds in pedigree programs, the temperate maize germplasm base has been narrowing (Hallauer and Miranda 1988; Tallury and Goodman 1999). Recent molecular and pedigree analysis of maize inbred lines with expired plant variety protection revealed that temperate (U.S) maize germplasm is mainly based on a few key inbreds (Mikel, 2006; Mikel and Dudley 2006; Nelson et al. 2008). This finding is consistent with previous studies that showed commercial hybrids trace back primarily to derivatives of about six to eight inbred lines (Goodman et al. 1988; Smith, 1988; Goodman, 1992). Despite the increasing grain yield in temperate maize there is also a concern on the increasinlgy limited genetic diversity in temperate germplasm and the potential to introgress exotic or tropical germplasm (Albrecht and Dudley 1987; Fan et al. 2010; Tallury and Goodman 1999; Nelson and Goodman 2008; Goodman, 1999; Goodman, 2004). Apart from diversifying the temperate maize germplasm base, studies have shown that tropical maize inbred lines crossed to temperate germplasm can be used in hybrid combinations without yield penalty in temperate environments (Tallury and Goodman 1999; Nelson and Goodman 2008).

Introgression of tropical maize germplasm into temperate germplasm has been studied by maize breeders. However, information on utilization of drought tolerant tropical maize germplasm to increase drought tolerance in temperate environments such as Turkey is lacking. We sought to investigate the potential of using drought tolerant tropical maize germplasm developed by CIMMYT in temperate hybrid combinations for evaluation under drought in Turkey.

The objectives of the study were to: i) analyze combining ability among tropical/subtropical germplasm and temperate Turkish maize inbreds under optimum and drought conditions for yield and yield related traits, ii) determine suitable parents for further breeding studies, iii) identify hybrids that have tolerance to drought, iv) generate knowledge on how to use tropical/subtropical maize germplasm for drought tolerance breeding in temperate maize.

\section{MATERIALS AND METHODS}

\section{Germplasm}

In the study, a set of drought tolerant tropical and subtropical maize inbred lines from different drought tolerant source populations La Posta Sequia (LPS), Drought Tolerant-Yellow (DTP-Y) and Drought TolerantWhite (DTP-W) developed by CIMMYT were evaluated in a preliminary study in Antalya, Turkey in 2010. Seven inbred lines were selected based on their adaptation and morphological characteristics from the study. Two welladapted, commercial, temperate inbreds from Stiff-Stalk (TK56) and Lancaster (TK72) backgrounds were also used in the study. Pedigree information about the inbreds is provided in Table 1. The nine inbred lines were crossed in a diallel design in 2011/12 to obtain 36 crosses excluding reciprocal crosses. Two popular high yielding commercial hybrids, P31A34 and DKC6589 were used as checks in the experiments.

Table 1. Pedigree information of the maize inbred lines

\begin{tabular}{ccccc}
\hline No & Inbred & Pedigree & $\begin{array}{c}\text { Country of } \\
\text { Origin }\end{array}$ & Source Population \\
\hline G1 & Ant I-96 & DTPYC9-F13-2-3-1-2-B & CIMMYT & $\begin{array}{c}\text { DTP-Y (Drought tolerant } \\
\text { population-yellow) } \\
\text { DTP-Y }\end{array}$ \\
G2 & Ant I-95 & DTPYC9-F72-1-2-1-1-B & CIMMYT & DTP-W (Drought tolerant \\
G3 & Ant I-97 & DTPW-C9-F16-1-1-1-1-B-B & CIMMYT & DTP-Y \\
G4 & Ant I-93 & DTPYC9-F46-1-7-1-1-B-B & CIMMYT & LPS (La Posta Sequia) \\
G5 & Ant I-91 & LPSC7F64-2-6-2-2-B-B & CIMMYT & DTP-Y \\
G6 & Ant I-92 & DTPYC9-F74-1-1-1-1-B-B & CIMMYT & DTP-Y \\
G7 & Ant I-98 & DTPYC9-F65-2-2-1-1-B-B & CIMMYT & Stiff-Stalk \\
G8 & TK 56 & FRB73 & Turkey & Lancaster \\
G9 & TK 72 & FRMo17 & Turkey & \\
\hline
\end{tabular}

\section{Experiments}

The study was conducted at Bati Akdeniz Agricultural Research Institute's Field Crops Department, Antalya (36052'N, 30045'E), Turkey over two years (2013 and 2014). The climate of the region is typically Mediterranean, i.e. mild and rainy in winter and dry and hot in summer. The soil of the research station is clay- loam in texture, unsalted and rich in calcium carbonate and alkali. Temperature and precipitation data during the period of the study was summarized in Table 2. During the reproductive stage of the crop (June to August) negligible precipitation was recorded in both years of experimentation resulting in highly favourable conditions in which to screen under drought stress. 
Table 2. Growing season climatic data of the experimental area

\begin{tabular}{ccccccrrrr}
\hline & \multicolumn{3}{c}{ Max. air temp. $\left({ }^{\mathbf{0}} \mathbf{C}\right)$} & \multicolumn{2}{c}{ Mean air temp. $\left({ }^{\mathbf{0}} \mathbf{C}\right)$} & \multicolumn{2}{c}{ Precipitation $(\mathbf{m m})$} \\
\cline { 2 - 9 } Month & $\mathbf{2 0 1 3}$ & $\mathbf{2 0 1 4}$ & $\begin{array}{r}\text { Long- } \\
\text { term }\end{array}$ & $\mathbf{2 0 1 3}$ & $\mathbf{2 0 1 4}$ & $\begin{array}{r}\text { Long- } \\
\text { term }\end{array}$ & $\mathbf{2 0 1 3}$ & $\begin{array}{r}\mathbf{2 0 1 4} \\
\text { Long- } \\
\text { term }\end{array}$ \\
\hline April & 37.4 & 27.7 & 33.0 & 17.7 & 16.6 & 16.2 & 34 & 41 \\
May & 35.8 & 30.1 & 34.7 & 22.5 & 20.2 & 21.0 & 56.0 & 27 & 46.0 \\
June & 38.8 & 42.1 & 39.7 & 25.4 & 25.3 & 25.9 & 0.0 & 1 & 4.2 \\
July & 39.7 & 42.2 & 41.6 & 28.0 & 27.5 & 28.9 & 16.0 & 0 & 3.0 \\
August & 41.5 & 42.8 & 41.0 & 28.7 & 27.5 & 28.8 & 0.0 & 5 & 1.8 \\
September & 40.6 & 34.0 & 38.3 & 24.7 & 25.0 & 25.1 & 19.0 & 20 & 27.0 \\
Mean & 39.3 & 36.5 & 39.1 & 25.9 & 23.7 & 25.9 & - & - & - \\
Sum & - & & - & - & & - & 91 & 94 & 141.8 \\
\hline
\end{tabular}

A total of 47 entries (36 half-diallel crosses, 2 commercial checks and 9 inbred lines were evaluated under water-stressed (WS) and well-watered (WW) conditions in adjacent experiments. Reproductive stage drought stress was induced in the WS experiments by withdrawing irrigation approximately 2-3 weeks before flowering until harvest as suggested by Banziger et al.
(2000) and Bruce et al. (2002). Soil water content in both WS and WW experiments was monitored using a gravimetric method (Black, 1965). The moisture changes in the 0-90 cm soil depth of the experiments in 2013 and 2014 are shown in Figure 1. Efforts were made to maintain field water holding capacity in the WW experiments through irrigation.
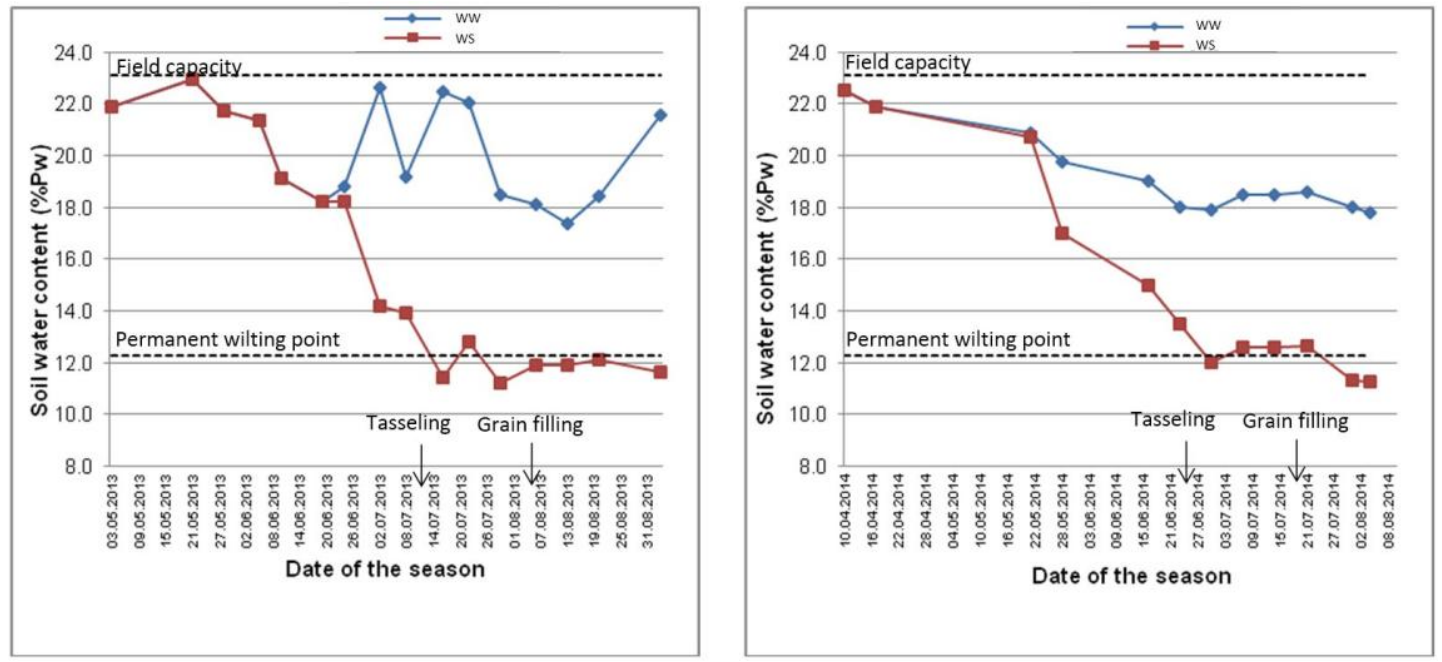

Figure 1. Change in soil moisture content prior to irrigation in WW and WS experiments obtained in 2013(left) and 2014 (right).

Experiments were designed as Randomized Complete Blocks with three replications. Plots consisted of two rows, 5 meters long with row spacing of 0.7 meters. After emergence, plants were thinned to approximately $0.2 \mathrm{~m}$ interplant density. Fertilization and plant protection measures were undertaken according to local recommendations.

\section{Data Analysis}

The traits evaluated in the research were measured according to Banziger et al. (2000) and UPOV (2009). Anthesis date (AD) was calculated as the number of days from sowing until $50 \%$ of plants in a plot had extruded anthers. Anthesis-silking interval (ASI) was calculated as the difference between silking date (when plants showed $50 \%$ silks) date and AD. Plant height (PH) was determined during the grain filling period and it was measured as the distance between ground level and the top of the tassel. In order to measure thousand kernel weight (TKW) 4 x 100 kernel samples from a plot was taken, averaged and then multiplied by 10 . To determine ears per plant (EPP), the number of ears with at least one fully developed grain was divided by the number of harvested plants. 5 ears were selected randomly from each plot and the number of kernels on the ear (KPE) was counted. Counted kernels were then divided by the number of ears to determine kernels per ear.

Analysis of variance was performed on data from 2013 and 2014 for yield and yield traits in WW and WS experiments. Years were considered as environment in the analyses and checks were excluded from the diallel analysis. A SAS program developed by Zhang et al. (2005) was used for Griffing's diallel method 2 model 1 (Griffing, 1956) analysis. In the model, parents and their half-diallels (reciprocal crosses excluded) were used. The General Linear Model (GLM) illustrates Griffing's methods for analyzing data:

$$
Y_{i j k l c}=\mu+\alpha_{l}+b_{k l}+v_{i j}+(\alpha v)_{i j l}+e_{i j k l c,}
$$


where $v_{i j}=g_{i+} g_{j+} s_{i j}$ and $(\alpha v) i j l=(\alpha g) i l+\left(\alpha g_{) j++}\left(\alpha S_{) i j l}\right.\right.$.

In the model, $Y_{i j k l c}=$ observed value of each experimental unit, $\mu=$ population mean, $\alpha_{l}=$ environment effect, $b_{k l}=$ block or replication effect in each environment, $\mathrm{v}_{i j}=\mathrm{F} 1$ hybrid effect, $(\alpha \nu)_{i j l}=$ interaction between environments and $\mathrm{F} 1$ hybrids, $e_{i j k l c}=$ residual effect, $g_{i}=$ GCA effect for $i$ th parent, $g_{j}=$ GCA effect for $j$ th parent, $s_{i j}=\mathrm{SCA}$ for $i j$ th F1 hybrid, $(\alpha g)_{i l}=$ interaction between GCA effect for $i$ th parent and environments, $(g)_{j}$ $=$ interaction between GCA effect for $j$ th parent and environments, (s)ijl = interaction between SCA effect for $i j$ th F1 hybrid and environments (Zhang and Kang 1997).

Drought Resistance Index (DI) (Lan, 1998), Stress Tolerance Index (STI) (Fernandez, 1992) and Yield Reduction Ratio (YRR) (Golestani and Assad 1998) indices were computed using Excel files.

$$
\begin{aligned}
& S T I=(Y s \times Y p) /\left(\overline{Y p}^{2}\right) \\
& D I=(Y s \times(Y s / Y p)) / \overline{Y s} \\
& Y R R=1-(Y s / Y p)
\end{aligned}
$$

In the above formulas, $\mathrm{Y}_{\mathrm{s}}, \mathrm{Y}_{\mathrm{p}}, \overline{\mathrm{Y}} s$ and $\overline{\mathrm{Y}} \mathrm{p}$ represent yield under stress (WS), yield under well watered (WW) for each genotype and experiment yield means in WS and WW conditions for all genotypes, respectively.

\section{RESULTS AND DISCUSSION}

Results of the combined analysis of variance for $\mathrm{AD}$, ASI, PH and TKW obtained from WW and WS experiments were shown in Table 3. According to the analysis, highly significant differences $(\mathrm{P}<0.01)$ were determined amongst genotypes in all investigated traits in both experiments. The analysis revealed that environments (years) were significant for both experiments except for $\mathrm{PH}$ in the WS experiments and KPE in WW experiments. Genotype by environment interactions was significant under both WW and WS experiments. General combining ability (GCA) effects of the inbreds and specific combining ability (SCA) of the hybrids were found to be highly significant $(\mathrm{P}<0.01)$ for all traits in both experiments and demonstrated the presence of both additive and non-additive effects. The magnitude of the GCA mean square and SCA mean square revealed the direction of gene action for the investigated traits. According to the ratio of the GCA/SCA mean square results, larger additive effects were determined for $\mathrm{AD}$ and ASI compared to other traits. The especially large GCA/SCA mean square of ASI under drought conditions suggests high levels of heritability. ASI is a key secondary trait that aids selection for drought tolerance in maize (Bolanos and Edmeades 1993; Edmeades et al. 1993; Byrne et al. 1995; Bolanos and Edmeades 1996; Ribaut et al 1997; Banziger et al. 2000; Ziyomo and Bernardo 2012). The ratio of GCA/SCA mean square of EPP was 3.80 and 1.29 in WW and WS experiments respectively, suggesting additive gene action for this trait as well. Nonadditive gene action was detected for PH (0.77), TKW $(0.52)$ and GY (0.83) in WS experiment (Table 4).

Table 3. Analysis of variance for anthesis day (AD), anthesis silking interval (ASI), plant height (PH) and thousand kernel weight (TKW) obtained from WW and WS conditions

\begin{tabular}{lcllllllll}
\hline \multirow{2}{*}{ Source of Variation } & \multicolumn{4}{c}{ AD } & \multicolumn{2}{c}{ ASI } & \multicolumn{2}{c}{ PH } & \multicolumn{2}{c}{ TKW } \\
\cline { 2 - 11 } & DF & \multicolumn{1}{c}{ WW } & WS & WW & WS & WW & WS & WW & WS \\
\hline Genotype (Gen) & 44 & $123.27^{* *}$ & $184.67^{* *}$ & $27.43^{* *}$ & $47.97^{* *}$ & $6.119 .49^{* *}$ & $5.634 .04^{* *}$ & $3.499 .49^{* *}$ & $6.762 .70^{* *}$ \\
Environment (Env) & 1 & $3.936 .89^{* *}$ & $2.594 .7^{* *}$ & $5.93^{* *}$ & $358.23^{* *}$ & $104.981 .39^{* *}$ & 358.23 & $51.819 .78^{* *}$ & $532.871 .21^{* *}$ \\
Gen x Env & 44 & $5.12^{* *}$ & $6.72^{* *}$ & $2.62^{* *}$ & $10.85^{* *}$ & $418.85^{* *}$ & $412.84^{* *}$ & $1.484 .12^{* *}$ & $1.860 .65^{* *}$ \\
GCA & 8 & $540.41^{* *}$ & $756.12^{* *}$ & $89.84^{* *}$ & $172.82^{* *}$ & $6.424 .89^{* *}$ & $4.564 .75^{* *}$ & $5.903 .62^{* *}$ & $3.897 .82^{* *}$ \\
GCA x Env & 8 & $12.03^{* *}$ & $19.54^{* *}$ & $3.56^{* *}$ & $27.047^{* *}$ & $377.24^{* *}$ & $364.65^{*}$ & $4.429 .22^{* *}$ & $1.685 .09^{* *}$ \\
SCA & 36 & $30.57^{* *}$ & $57.69^{* *}$ & $17.08^{* *}$ & $20.23^{* *}$ & $6.051 .63^{* *}$ & $5.875 .66^{* *}$ & $2.965 .24 * *$ & $7.399 .35^{* *}$ \\
SCA x Env & 36 & $3.59^{* *}$ & $3.87^{* *}$ & $2.42^{* *}$ & $7.26^{* *}$ & $428.09^{* *}$ & $423.55^{* *}$ & $829.65^{* *}$ & $1.899 .66^{* *}$ \\
GCA / SCA & - & 17.7 & 13.1 & 5.25 & 8.54 & 1.06 & 0.77 & 1.99 & 0.52 \\
CV $(\%)$ & - & 1.5 & 1.79 & 27.9 & 20.9 & 3.58 & 5.99 & 6.99 & 11.76 \\
Mean (experiment) & - & 75.4 & 76.5 & 3.18 & 5.47 & 250.35 & 204.57 & 253.69 & 173.39 \\
\hline
\end{tabular}

*.**: statistically significant at 0.05 and 0.01 level respectively

Mean GY of the WS trials (2013 and 2014) was $1673.81 \mathrm{~kg} \mathrm{ha}^{-1}$ with CV of 20.81 (Table 4). Mean GY of the WW trials (2013 and 2014) was $6907.14 \mathrm{~kg} \mathrm{ha}^{-1}$ with a $\mathrm{CV}$ of 15.41 . Overall WS trials reported a $76 \%$ reduction in GY relative to optimal (normal) WW conditions (Table 4). The yield reduction due to drought showed that, drought was severe enough to test the genotypes in the study as stated by Bruce et al. (2002). 
Table 4. Analysis of variance for number of ear per plant (EPP), number of kernel per ear (KPE) and grain yield (GY) obtained from WW and WS conditions

\begin{tabular}{lcllllll}
\hline Source of Variation & \multicolumn{2}{c}{ EPP } & \multicolumn{2}{c}{ KPE } & \multicolumn{1}{c}{ GY } \\
\hline & DF & WW & WS & WW & \multicolumn{1}{c}{ WS } & WW & WS \\
\hline Genotype (Gen) & 44 & $0.073^{* *}$ & $0.15^{* *}$ & $152.109 .04^{* *}$ & $159.272 .04^{* *}$ & $55.936 .523^{* *}$ & $6.669 .535 .0^{* *}$ \\
Environment (Env) & 1 & $0.51^{* *}$ & $12.94^{* *}$ & 1.315 .62 & $267.152 .03^{* *}$ & $128.973 .774^{* *}$ & $209.732 .479 .9^{* *}$ \\
Gen x Env & 44 & $0.072^{* *}$ & $0.11^{* *}$ & $9.798 .90^{* *}$ & $19.546 .16^{* *}$ & $2.124 .687^{* *}$ & $1.605 .219 .9 * *$ \\
GCA & 8 & $0.19^{* *}$ & $0.18^{* *}$ & $225.036 .58^{* *}$ & $250.455 .11^{* *}$ & $76.619 .190 .52^{* *}$ & $5.731 .020 .26^{* *}$ \\
GCA x Env & 8 & $0.24^{* *}$ & $0.41^{* *}$ & $16.375 .19^{* *}$ & $29.604 .72^{* *}$ & $3.182 .222 .37 * *$ & $1.072 .461 .26^{* *}$ \\
SCA & 36 & $0.05^{* *}$ & $0.14^{* *}$ & $135.903 .42^{* *}$ & $139.009 .14^{* *}$ & $51.340 .374 .27^{* *}$ & $6.878 .093 .86^{* *}$ \\
SCA x Env & 36 & $0.04^{* *}$ & $0.04^{* *}$ & $8.337 .50^{* *}$ & $17.310 .93^{*}$ & $1889678.74^{* *}$ & $1.723 .610 .75^{* *}$ \\
GCA / SCA & - & 3.8 & 1.29 & 1.66 & 1.80 & 1.49 & 0.83 \\
CV (\%) & - & 9.37 & 16.20 & 14.06 & 18.23 & 15.41 & 20.81 \\
Mean (experiment) & - & 0.99 & 0.59 & 509.54 & 306.66 & 6907.14 & 1673.81 \\
\hline
\end{tabular}

***: statistically significant at 0.05 and 0.01 level respectively

GCA results of the nine inbreds are presented in Table 5 and Table 6. GCA effects differed between the WW and WS experiments although in general, positive GCAs under WW corresponded to positive GCAs under WS and vice versa for most traits.

Table 5. GCA effects for anthesis day (AD), anthesis silking interval (ASI), plant height (PH) and thousand kernel weight (TKW) obtained from WW and WS conditions

\begin{tabular}{crrrrrrrr}
\hline \multirow{2}{*}{ Inbred } & \multicolumn{2}{c}{ AD } & \multicolumn{2}{c}{ ASI } & \multicolumn{2}{c}{ PH } & \multicolumn{1}{c}{ TKW } \\
\cline { 2 - 8 } & WW & WS & WW & WS & WW & \multicolumn{1}{c}{ WS } & \multicolumn{1}{c}{ WW } & \multicolumn{1}{c}{ WS } \\
\hline G1 & $-1.84^{* *}$ & $-2.47^{* *}$ & $-1.09^{* *}$ & $-2.24^{* *}$ & $-23.04^{* *}$ & $-15.11^{* *}$ & $16.80^{* *}$ & 4.67 \\
G2 & 0.28 & 0.34 & -0.03 & $0.52^{*}$ & $-6.26^{*}$ & $-6.65^{* *}$ & $-9.03^{* *}$ & -8.09 \\
G3 & $1.92^{* *}$ & $2.15^{* *}$ & $1.03^{* *}$ & $0.91^{* *}$ & 5.18 & $9.05^{* *}$ & -1.64 & 4.99 \\
G4 & $3.36^{* *}$ & $4.17^{* *}$ & $2.12^{* *}$ & $2.64^{* *}$ & $10.71^{* *}$ & -1.20 & $-6.57^{*}$ & $-13.00^{*}$ \\
G5 & $3.48^{* *}$ & $3.99^{* *}$ & -0.02 & -0.04 & 4.90 & -1.24 & 4.15 & 2.82 \\
G6 & $1.31^{*}$ & $1.90^{* *}$ & $0.59^{* *}$ & $1.14^{* *}$ & $6.40^{*}$ & $4.61^{* *}$ & -3.93 & 0.71 \\
G7 & $-0.4 n s$ & -0.78 & 0.15 & $0.59^{*}$ & 0.47 & $-5.41^{* *}$ & -0.69 & 5.89 \\
G8 & $-3.94^{* *}$ & $-4.44^{* *}$ & $-1.43^{* *}$ & $-1.72^{* *}$ & 1.34 & $5.14^{* *}$ & $-11.21^{* *}$ & -7.54 \\
G9 & $-4.19^{* *}$ & $-4.86^{* *}$ & $-1.32^{* *}$ & $-1.80^{* *}$ & 0.30 & $10.82^{* *}$ & $12.12^{* *}$ & 9.55 \\
\hline
\end{tabular}

***: statistically significant at 0.05 and 0.01 level respectively

Table 6. GCA effects for number of ear per plant (EPP), number of kernel per ear (KPE) and grain yield (GY) obtained from WW and WS conditions

\begin{tabular}{rrrrrrr}
\hline & EPP & \multicolumn{1}{c}{ KPE } & \multicolumn{1}{c}{ GY } \\
\hline Inbred & WW & WS & WW & WS & WW & WS \\
\hline G1 & $0.05^{* *}$ & $0.08^{*}$ & 1.61 & $26.78^{* *}$ & $1051.14^{* *}$ & 230.91 \\
G2 & $-0.06^{* *}$ & -0.03 & -11.04 & $11.65^{* *}$ & $-683.68^{* *}$ & -35.03 \\
G3 & -0.01 & -0.02 & $-55.16^{* *}$ & $-39.40^{* *}$ & $-973.94 * *$ & -150.84 \\
G4 & -0.03 & -0.01 & $-89.19^{* *}$ & $-84.54^{* *}$ & $-1626.48^{* *}$ & $-329.94 *$ \\
G5 & $0.10^{* *}$ & $0.09^{*}$ & 7.07 & $-31.66^{* *}$ & 327.80 & 247.64 \\
G6 & $-0.05^{* *}$ & -0.05 & -15.86 & $-60.46^{* *}$ & $-755.43^{* *}$ & $-434.41^{* *}$ \\
G7 & $0.04^{*}$ & -0.06 & -4.39 & $-1.87^{* *}$ & 40.20 & -181.05 \\
G8 & -0.01 & 0.00 & $114.30^{* *}$ & $94.07^{* *}$ & $1372.85^{* *}$ & 246.79 \\
G9 & -0.03 & 0.00 & $52.64 * *$ & $85.42^{* *}$ & $1247.54 * *$ & $405.93 * *$ \\
\hline ***: statistically significant at 0.05 and 0.01 level respectively & & & & &
\end{tabular}

In terms of flowering traits, the tropical inbred $\mathrm{G} 1$, gave significant and negative GCA effect for AD under both conditions indicating that the line can be used to select for earliness. Temperate inbred lines G8 and G9 gave significant and negative GCA values for $\mathrm{AD}$ as expected due to their adaptation. When GCA results of the ASI investigated, it was determined that tropical originated inbred lines G1 and G5 had potential breeding value for drought tolerance. Also, Temperate inbred lines G8 and G9 showed good performance in terms of ASI in both experiments. In terms of PH, G4 and G6 genotypes gave positive and significant GCA results in WW conditions; while G3, G6, G8 and G9 showed positive and significant GCA effects in WS conditions. G1 and G9 inbred lines were the best genotypes that showed positive and significant GCA value for TKW in WW experiment. Non-significant GCA values were prevalence in WS conditions for TKW except G4. Differences in EPP amongst entries was limited although positive and significant EPP GCA values were observed for the 
tropical inbreds G1, G5 and G7 under WW conditions and G1 and G5 under WS conditions. This could be related to the fact that multicobbing remains common in some tropical germplasm whilst being selected against in temperate regions such as Turkey. More ears per plant has been suggested as a secondary selection trait for drought tolerance (Banziger et al. 2000; Bao-Cheng et al. 2010). Therefore, G1 and G5 tropical inbreds can be selected for improving drought tolerance in temperate maize. Positive and significant KPE GCA values were obtained from tropical inbreds G1 and G5 in addition to temperate inbreds G8 and G9 temperate suggesting that some tropical lines can be used to improve this trait.

Inbreds G1, G8 and G9 gave significant and positive GCA for GY under WW. All three inbreds also had positive GCA under WS conditions although only G9 was significant. G5 is one of the most widely used abiotic stress donor line in the tropics for both drought and poor soil fertility and had positive GCA under both WW and WS conditions although non-significant. The highly significant positive GCAs for the two temperate lines are an indication of better adaptation and yield potential of temperate germplasm.

Lower GCAs amongst the tropical donor lines was not unsurprising given that most lines were derived from the same DTPYC9 source population which may have resulted in limited heterosis. The one line from a different source population, G5 from LaPosta population, demonstrated positive GCAs under both WW and WS conditions. The tropical inbreds were also unadapted to the screening environment especially in terms of photoperiod sensitivity and rust tolerance. Nonetheless, inbreds G1 and G5 produced comparable GCA to the temperate lines suggesting that introgression of specific tropical inbreds will likely enhance heterosis and the germplasm diversity base in Turkey.

GCA analysis suggests that the tropical inbreds G1 and G5 from Drought Tolerant Populations Yellow and LaPostaSequi respectively, may be the most suitable tropical introgression candidates for a number of traits for maize breeding in Turkey. Evaluation of a wider selection of tropical and subtropical germplasm is likely to yield additional inbreds that may have utility in temperate breeding programs.

SCA results of the hybrids for $\mathrm{AD}, \mathrm{ASI}, \mathrm{PH}, \mathrm{TKW}$, EPP, KPE and GY obtained from WW and WS conditions are presented in Table 7 and 8. SCA values differed under WW and WS conditions suggesting specific adaptation to drought stress amongst hybrids. Hybrid G1xG4 had the highest negative SCA effect for AD under WW conditions, while hybrid $\mathrm{G} 4 \mathrm{xG} 8$ (tropical $\mathrm{x}$ temperate) was the best for $\mathrm{AD}$ in WS conditions followed by hybrids G2xG5 (Tropical $x$ Tropical) and G1xG4 (Tropical $x$ Tropical). Inbreds G3 and G6 were the best combiners (a tropical hybrid) for ASI in WW experiments. Hybrid G6xG8 (tropical x temperate) was the best for ASI under WS conditions. A tropical x temperate hybrid, G1xG8 had highest SCA value for $\mathrm{PH}$ in both WW and WS conditions. The highst SCA values for TKW were recorded from $\mathrm{G} 3 \mathrm{xG} 8$ (tropical $\mathrm{x}$ temperate) in WW and G3xG6 (tropical $x$ tropical) in WS conditions. Tropical $x$ temperate hybrids G4x G8 and G5xG9 had the highest SCA for EPP under WW and WS conditions respectively. Inbreds G2 and G3 were the best combiners in terms of KPE under WW conditions, while inbreds G4 and G8 were the best under WS.

Results of SCA for GY revealed that tropical $x$ temperate hybrids ranked one and two of the 36 hybrids evaluated under WW conditions. This is likely caused by high heterosis due to the genetic distances and high yield potential in the temperate germplasm. Similar results were observed under WS where the top three hybrids were tropical $\mathrm{x}$ temperate. In general, the SCA analysis showed that tropical $\mathrm{x}$ temperate hybrids had higher SCA values than tropical $\mathrm{x}$ tropical hybrids or temperate $\mathrm{x}$ temperate hybrids. This finding suggests that tropical $\mathrm{x}$ temperate hybrid combinations can be extremely useful in addressing severe reproductive stage drought in Turkish maize production systems.

Two high yielding, commercial, single cross hybrids, P31A34 and DKC6589, were also used as checks against the half diallel hybrids in order to assess their performance relative to widely cultivated varieties in Turkey. Combined mean GY results of the test hybrids and checks in WW and WS experiments were shown in Figure 2. Although tropical $x$ temperate hybrid G5xG9 was the best yielder under WS conditions, the commercial checks were surprisingly drought tolerant relative to the diallel crosses ranking second and third. The commercial checks were also the highest yielders under WW conditions. It is likely that adaptation to local conditions in Turkey played an important role. Several researchers (Duvick 1977, 1992; Hallauer et al. 1988; Russel, 1991; Carena and Cross 2003; Tollenar and Wu 1999; Tollenar, 2000) have also attributed increased stress tolerance in modern temperate maize germplasm to indirect selection through planting at high plant densities. 
Table 7. SCA effects for anthesis day (AD), anthesis silking interval (ASI), plant height (PH) and thousand kernel weight (TKW) obtained from WW and WS conditions

\begin{tabular}{|c|c|c|c|c|c|c|c|c|}
\hline \multirow{2}{*}{ Hybrid } & \multicolumn{2}{|c|}{ AD } & \multicolumn{2}{|c|}{ ASI } & \multicolumn{2}{|c|}{$\mathbf{P H}$} & \multicolumn{2}{|c|}{ TKW } \\
\hline & $\mathbf{W W}$ & WS & $\mathbf{W W}$ & $\mathbf{W S}$ & $\mathbf{W W}$ & WS & $\mathbf{W W}$ & WS \\
\hline G1xG2 & -1.18 & -1.00 & 0.11 & -1.24 & 11.62 & $27.4^{* *}$ & $22.11 *$ & 15.8 \\
\hline G1xG3 & -1.99 & -1.98 & 0.21 & -0.36 & $21.51 *$ & 5.49 & $23.64 *$ & 25.1 \\
\hline G1xG4 & -3.09 & $-3.17 *$ & $-1.88 * *$ & $-2.7 * *$ & $19.98 *$ & $18.1 * *$ & $25.41 *$ & $44.2 *$ \\
\hline G1xG5 & -2.38 & -1.98 & -0.41 & -1.18 & 2.63 & 7.95 & 3.03 & 19.0 \\
\hline G1xG6 & -1.38 & -1.73 & $-1.02 *$ & $-1.7 *$ & 6.13 & $18.8 * *$ & 18.73 & 28.2 \\
\hline G1xG7 & -0.17 & -0.21 & -0.41 & -0.15 & 11.72 & $12.6^{*}$ & 18.89 & 16.1 \\
\hline G1xG8 & 0.20 & -0.56 & $0.83 *$ & 1.5 & $31.03 * *$ & $29.2 * *$ & -8.67 & 0.83 \\
\hline G1xG9 & 1.45 & 0.03 & 0.23 & 0.58 & $19.89 *$ & $14.2 *$ & $-11.4 * *$ & -4.91 \\
\hline G2xG3 & -0.94 & -2.12 & $-1.35 * *$ & 0.61 & $30.06^{* *}$ & 9.54 & 7.91 & 7.71 \\
\hline $\mathrm{G} 2 \mathrm{xG} 4$ & -1.38 & -1.97 & $0.89 *$ & $2.21 * *$ & $20.03 *$ & $22 * *$ & 12.75 & 32.7 \\
\hline G2xG5 & -2.00 & $-3.62 *$ & $-1.97 * *$ & -1.11 & 6.01 & 6.83 & -1.93 & -1.02 \\
\hline G2xG6 & 1.16 & -1.36 & $-0.91 *$ & 0.38 & 15.68 & $21.2 * *$ & 8.46 & 13.1 \\
\hline G2xG7 & 0.71 & -0.02 & -0.3 & 0.26 & 15.6 & $14.7 * *$ & 3.92 & 4.91 \\
\hline G2xG8 & -1.25 & -1.36 & -0.23 & -1.42 & 11.07 & $22 * *$ & 6.38 & 4.86 \\
\hline G2xG9 & -1.50 & -1.61 & 0.0 & -0.68 & 14.94 & $13.4^{*}$ & -0.84 & 12.7 \\
\hline G3xG4 & -0.02 & 1.88 & $1.00 *$ & $2.32 * *$ & 13.09 & 10.3 & 7.83 & 20.3 \\
\hline G3xG5 & -1.47 & -1.94 & 0.14 & 0.00 & 8.41 & $14.1 *$ & 6.8 & -0.6 \\
\hline G3xG6 & -0.14 & 2.32 & $3.36 * *$ & $3.82 * *$ & 17.24 & $21.3 * *$ & -9.92 & $53.0 *$ \\
\hline G3xG7 & 0.24 & -0.33 & $1.14 * *$ & 0.70 & $24.99 * *$ & $13.3^{*}$ & 8.85 & 11.8 \\
\hline G3xG8 & -1.22 & -1.84 & -0.62 & -0.98 & 6.63 & $16.1 * *$ & $30.51 * *$ & 21.2 \\
\hline G3xG9 & -1.64 & -1.76 & -0.73 & -0.41 & 3.5 & 9.24 & 16.94 & 13.4 \\
\hline G4xG5 & 2.75 & 1.38 & $1.88 * *$ & $1.94 *$ & $29.54 * *$ & $26.7 * *$ & 10.89 & -11.9 \\
\hline G4xG6 & -0.41 & 0.14 & -0.73 & $1.76^{*}$ & -6.12 & -5.81 & -5.47 & $-50.0 *$ \\
\hline G4xG7 & -1.53 & $-3.02 *$ & $-1.45^{* *}$ & -0.70 & 10.63 & $16.7 * *$ & 8.9 & 24.9 \\
\hline G4xG8 & -2.49 & $-3.70 * *$ & $-2.21 * *$ & $-2.05^{*}$ & $18.44^{*}$ & $17.3 * *$ & 6.15 & 27.0 \\
\hline G4xG9 & -1.58 & -1.27 & $-2.32 * *$ & $-2.30 * *$ & 7.97 & $15.2 * *$ & 17.94 & 25.2 \\
\hline G5xG6 & 1.30 & 1.98 & $1.41 * *$ & $1.77 *$ & 17.86 & $20.2 * *$ & 19.07 & $41.6^{*}$ \\
\hline G5xG7 & -0.32 & 0.00 & $2.85 * *$ & $3.32 * *$ & $23.45^{*}$ & $14.9 * *$ & $26.59 *$ & 35.4 \\
\hline G5xG8 & -2.94 & -2.02 & -0.74 & -1.53 & 8.92 & 9.71 & 3.22 & 18.3 \\
\hline G5xG9 & -1.53 & -1.26 & -0.18 & -1.12 & 16.45 & $18.4 * *$ & -2.78 & 14.7 \\
\hline G6xG7 & -1.99 & $-3.08 *$ & $-0.92 *$ & -1.53 & -1.22 & $-15.9 * *$ & 2.04 & -3.77 \\
\hline G6xG8 & -0.60 & $-2.92 *$ & $-0.85^{*}$ & $-2.55 * *$ & 10.42 & -8.14 & 6.38 & 4.34 \\
\hline G6xG9 & -0.86 & -2.50 & $-0.95^{*}$ & -0.8 & 12.62 & 6.01 & 16.06 & -0.96 \\
\hline G7xG8 & -0.40 & -1.08 & -0.58 & 0.5 & $21.01 *$ & $25^{* *}$ & -13.3 & -14.9 \\
\hline G7xG9 & -0.32 & -0.48 & -0.68 & 0.24 & 8.71 & 10.5 & 7.65 & 21.0 \\
\hline G8xG9 & -0.28 & -0.33 & 0.73 & $0.89 *$ & -5.48 & $-14.2 *$ & 12.16 & -7.39 \\
\hline
\end{tabular}


Table 8. SCA effects for number of ear per plant (EPP), number of kernel per ear (KPE) and grain yield (GY) obtained from WW and WS conditions

\begin{tabular}{|c|c|c|c|c|c|c|c|c|c|c|c|}
\hline \multirow{3}{*}{$\begin{array}{l}\text { Hybrid } \\
\text { G1xG2 }\end{array}$} & \multicolumn{3}{|c|}{ EPP } & \multicolumn{4}{|c|}{ KPE } & \multicolumn{4}{|c|}{ GY } \\
\hline & \multicolumn{2}{|c|}{ WW } & WS & \multicolumn{2}{|l|}{ WW } & \multicolumn{2}{|c|}{ WS } & \multicolumn{2}{|l|}{ WW } & \multicolumn{2}{|l|}{ WS } \\
\hline & -0.01 & & 0.18 & 99.88 & $* *$ & 92.3 & $* *$ & 1228.13 & $*$ & 1105.6 & $*$ \\
\hline G1xG3 & -0.03 & & 0.11 & 97.67 & $* *$ & 106 & $* *$ & 2373.29 & $* *$ & 733.91 & \\
\hline G1xG4 & 0.04 & & 0.11 & 131.9 & $* *$ & 134 & $* *$ & 3315.66 & $* *$ & 743.86 & \\
\hline G1xG5 & 0.01 & & 0.13 & 34.11 & & 142 & $* *$ & 1791.83 & $* *$ & 764.67 & \\
\hline G1xG6 & 0.01 & & 0.14 & 24.03 & & 48.2 & & 1913.99 & $* *$ & 615.25 & \\
\hline G1xG7 & 0.04 & & 0.01 & -4.77 & & 26.1 & & 972.27 & & 244.83 & \\
\hline G1xG8 & -0.01 & & 0.19 & 30.72 & & 84.8 & $* *$ & -79.98 & & 217.01 & \\
\hline G1xG9 & 0.09 & & 0.00 & 27.7 & & 33.3 & & 18.7 & & -390.96 & \\
\hline $\mathrm{G} 2 \mathrm{xG} 3$ & 0.12 & $*$ & -0.06 & 162.8 & $* *$ & 131 & $* *$ & 2575.8 & $* *$ & 288.05 & \\
\hline $\mathrm{G} 2 \mathrm{xG} 4$ & -0.05 & & 0.00 & 46.85 & & -1.1 & & 361.12 & & -240.8 & \\
\hline G2xG5 & -0.08 & & -0.06 & 65.26 & $*$ & 174 & $* *$ & 2000.96 & $* *$ & 731.62 & \\
\hline G2xG6 & 0.03 & & 0.07 & 73.35 & $*$ & 18.5 & & 713.87 & & 153.41 & \\
\hline $\mathrm{G} 2 \mathrm{xG} 7$ & -0.04 & & -0.01 & 57.71 & & 74.4 & * & 1203.11 & $*$ & 275.49 & \\
\hline $\mathrm{G} 2 \mathrm{xG} 8$ & 0.02 & & 0.07 & 82.53 & & 84.5 & $* *$ & 565.29 & & 175.26 & \\
\hline G2xG9 & 0.04 & & 0.08 & 59.85 & $*$ & 52.3 & & 476.91 & & 524.63 & \\
\hline G3xG4 & -0.11 & & 0.07 & -146 & $* *$ & -64.8 & $*$ & -2214.37 & $* *$ & -706.42 & \\
\hline G3xG5 & 0.02 & & 0.00 & 134.9 & $* *$ & 113 & $* *$ & 1470.05 & $* *$ & 543.76 & \\
\hline G3xG6 & -0.05 & & -0.10 & 80.47 & $* *$ & 3.87 & & -593.14 & & -426.95 & \\
\hline G3xG7 & -0.07 & & -0.03 & 140.8 & $* *$ & 26.5 & & 898.93 & & 49.92 & \\
\hline G3xG8 & -0.03 & & 0.14 & 67.99 & $*$ & 36.5 & & 1488.11 & $* *$ & 855.41 & \\
\hline G3xG9 & 0.13 & $*$ & 0.08 & 82.64 & $* *$ & 76.3 & * & 2837.64 & $* *$ & 1151.19 & $* *$ \\
\hline G4xG5 & 0.17 & $* *$ & -0.07 & -70.8 & $*$ & -131 & $* *$ & -2219.78 & $* *$ & -690.64 & \\
\hline G4xG6 & -0.06 & & -0.12 & -12.7 & & -47.8 & & -1289.59 & $*$ & -537.35 & \\
\hline G4xG7 & 0.04 & & 0.13 & 125.4 & $* *$ & 70.8 & $*$ & 1606.94 & $* *$ & 933.12 & $*$ \\
\hline G4xG8 & 0.18 & $* *$ & 0.10 & 159.4 & $* *$ & 222 & $* *$ & 3983.82 & $* *$ & 1486.17 & $* *$ \\
\hline G4xG9 & 0.13 & $*$ & 0.07 & 117.8 & $* *$ & 63.3 & & 2161.05 & $* *$ & 731.74 & \\
\hline G5xG6 & -0.05 & & -0.07 & 20.58 & & -34.2 & & -1048.78 & & -200.25 & \\
\hline G5xG7 & 0.00 & & -0.05 & -10.1 & & -53.8 & & -783.87 & & -219.5 & \\
\hline G5xG8 & -0.08 & & 0.02 & 100.3 & $* *$ & 55.3 & & 1481.97 & $* *$ & 515.77 & \\
\hline G5xG9 & -0.01 & & $0.23 *$ & 79.08 & $* *$ & 186 & $* *$ & 3658.85 & $* *$ & 2337.59 & $* *$ \\
\hline G6xG7 & 0.07 & & 0.12 & 99.53 & $* *$ & 114 & $* *$ & 1926.56 & $* *$ & 614.79 & \\
\hline G6xG8 & 0.11 & & 0.19 & 125.7 & $* *$ & 116 & $* *$ & 2688.49 & $* *$ & 982.25 & $*$ \\
\hline G6xG9 & 0.04 & & 0.06 & 45.0 & & 43.6 & & 2224.93 & $* *$ & 116.29 & \\
\hline G7xG8 & -0.02 & & 0.09 & 25.05 & & 51.0 & & 944.8 & & 127.3 & \\
\hline G7xG9 & 0.00 & & 0.04 & 5.53 & & 83.1 & * & 848.87 & & 244.05 & \\
\hline G8xG9 & 0.00 & & -0.06 & 34.68 & & -71.2 & $*$ & 65.94 & & -625.87 & \\
\hline
\end{tabular}

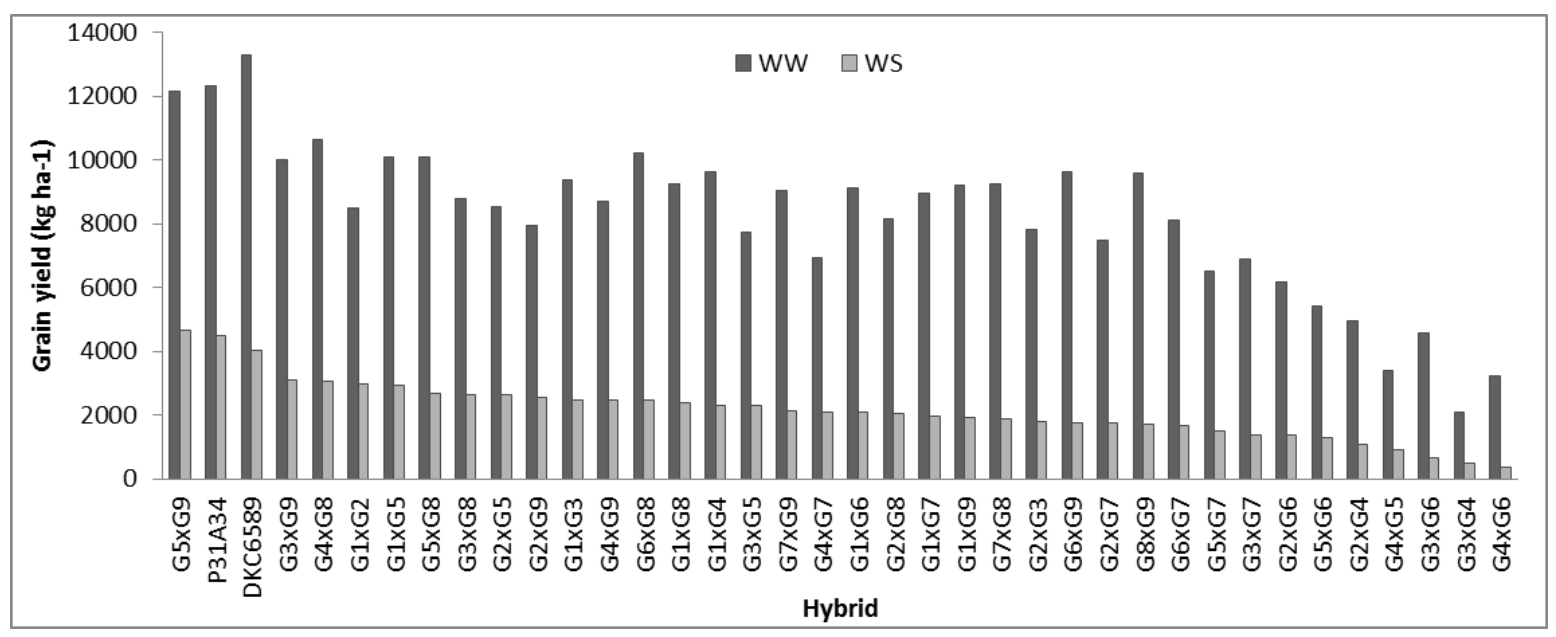

Figure 2. Mean GY of the half-diallel hybrids and commercial checks in WW and WS experiments 
Due to the complexity of drought tolerance various selection indices have been developed incorporating various secondary traits (Hao et al. 2011). These include the Drought Resistance Index (DI) (Lan, 1998), Stress Tolerance Index (STI) (Fernandez, 1992) and Yield Reduction Ratio (YRR) (Golestani and Assad 1998). These three indices are commonly used to identify high yielding genotypes under both stress and nonstress conditions. DI, STI and YRR results for GY under WS and WW conditions are shown in Figure 3. According to the index results, the tropical $x$ temperate hybrid, G5xG9, was the best for all three selection indices under both WW and WS conditions (Figure 3).

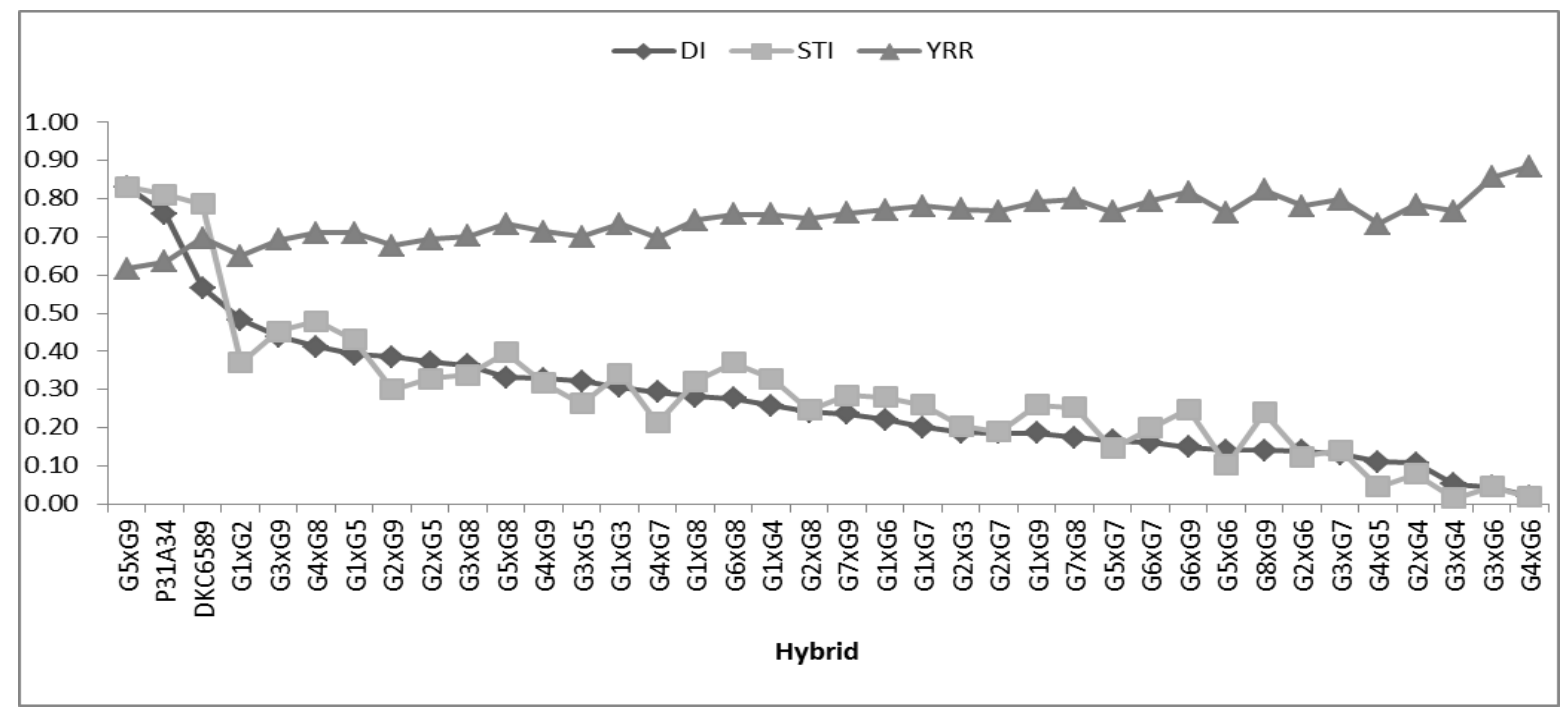

Figure 3. Drought resistance index (DI), stress tolerance index (STI) and yield reduction ratio (YRR) of the hybrids and checks for GY

\section{LITERATURE CITED}

In conclusion, combining ability analysis showed that additive genetic variance was more prevalence than nonadditive variance in most cases for grain yield and secondary traits except PH, TKW and GY in WS. Tropical

inbreds G1 and G5, derivatives of DTP-Y and LPS source populations respectively, were comparable with adapted temperate commercial lines in terms of GCA results. The SCA analysis showed that tropical $\mathrm{x}$ temperate hybrids had higher SCA values than tropical $\mathrm{x}$ tropical hybrids suggesting that tropical $\mathrm{x}$ temperate hybrids can be useful for drought tolerance in temperate regions. In particular, tropical x temperate hybrid G5 x G9, demonstrated very high yield potential under both WS and WW conditions. Our findings suggest that tropical drought tolerant germplasm is likely to have high utility in temperate maize breeding programs. High SCA and good GCA under WS conditions were observed despite sampling a relatively small number of tropical donors. Evaluating and introgression of further sources of tropical drought tolerance can broaden the genetic base of the temperate maize breeding programs.

\section{ACKNOWLEDGEMENTS}

The authors would like to thank the General Directorate of Agricultural Research and Policies (TAGEM) of the Ministry of Food, Agriculture and Livestock of Turkey for supporting this research.
Albrecht, B., J.W. Dudley. 1987. Evaluation of 4 maize populations containing different proportions of exotic germplasm. Crop Science, 27: 480-486.

Ashraf, M. 2010. Inducing drought tolerance in plants: Recent Advances. Biotechnology Advances, 28: 169-183

Banziger, M., G.O., Edmeades, D. Beck, M. Bellon. 2000. Breeding for drought and nitrogen stress tolerance in maize, from theory to practice. Mexico, D.F. CIMMYT

Bao-Cheng, S., L. Cheng, S. Yun-Su, S. Yan-Chun, W. Tian-Yu, L. Yu. 2010. Relationships between ear number per plant and drought tolerance in maize hybrids. Xinjiang Agricultural Sciences, 2007-05.

Beck, D., F.J. Betran, G.O. Edmeades, M. Banziger and M. Willcox. 1996. From landrace to hybrid: strategies for the use of source populations and lines in the development of drought-tolerant cultivars. In G.O. Edmeades et al. (ed.) Developing Drought and Low N Tolerant Maize. Proceedings of a Symposium, El Batan. 25-29 March 1996. CIMMYT, El Batan, Mexico.

Black, C.A. 1965. Methods of Soil Analysis: Part I Physical and mineralogical properties. American Society of Agronomy, Madison, Wisconsin, USA.

Bolanos, J., G.O. Edmeades. 1993. Eight cycle of selection for drought tolerance in lowland tropical maize. II. Responses in reproductive behavior. Field Crops Research, 31: 269-289.

Bolanos, J., G.O. Edmeades. 1996. The Importance of the anthesis silking interval in breeding for drought tolerance in tropical maize. Field Crops Research, 48: 65-80.

Bruce, W.B., G.O. Edmeades, T.C. Barker. 2002. Molecular and physiological approaches to maize improvement for drought tolerance. Journal of Experimental Botany, 53: 13-25.

Byrne, P.F., J. Bolanos, G.O. Edmeades, and D.L. Eaton. 1995. Gains from selection under drought versus multilocation 
testing in related tropical maize populations. Crop Sci. 35:63-69.

Carena, M.J., and H.Z. Cross. 2003. Plant density and maize germplasm improvement in the northern Corn Belt. Maydica, 48: 105-111.

Cooper, M., C. Gho, R. Leafgren, T. Tang, and C. Messina. 2014. Breeding drought-tolerant maize hybrids for the US corn-belt: discovery to product. Journal of Experimental Botany, doi:10.1093/jxb/eru064

Duvick, D.N. 1992. Genetic contributions to advances in yield of U.S maize. Maydica, 37:69-87

Duvick, D.N. 1977. Genetic rates of gain in hybrid maize during the last 40 years. Maydica 22:187-196.

Edmeades, G.O., M. Banziger, M. Cortes, and A. Ortega. 1996. From stress-tolerant populations to hybrids: The role of source germplasm. p. 263-273. In G.O. Edmeades et al. (ed.) Drought- and low N-tolerant maize. Proceedings of a Symposium, El Batan. 25-29 March 1996. CIMMYT, El Batan, Mexico.

Edmeades, G.O., J. Bolanos, S.C. Chapman, H.R. Lafitte, M. Banziger. 1999. Selection improves drought tolerance in tropical maize populations: I. Gains in biomass, grain yield, and harvest index. Crop Sci. 39:1306-1315.

Edmeades, G.O., J. Bolanos, M. Hernandez, S. Bello. 1993 Causes for silk delay in a lowland tropical maize population. Crop Science, 33: 1029-1035.

Fan, X.M., Y.D. Zhang, L. Liu, H.M. Chen, W.H. Yao, M Kang, J.Y. Yang. 2010. Screening tropical germplasm by temperate inbred testers. Maydica, 55: 55-63

FAOSTAT, 2014. Access date: 02.03.2014. http://faostat.fao.org/

Fernandez, G.C.J. 1992. Effective selection criteria for assessing plant stress tolerance. Proceeding Of The International Symposium On Adaptation Of Vegetables And Other Food Crops İn Temperature And Water Stress, Aug. 13-16, Shanhua, Taiwan, pp. 257-270.

Fischer, K.S., G.O. Edmeades, E.C. Johnson. 1989. Selection for the improvement of maize yield under moisture-deficits. Field Crops Research, 22:3, 227-243

Golestani, S.A. and M.T. Assad. 1998. Evaluation of four screening techniques for drought resistance and their relationship to yield reduction ratio in wheat. Euphytica, 103: 293-299.

Goodman, M.M. 1992. Choosing and using tropical corn germplasm.Ann Corn Sorghum Ind Res Conf Proc, 47 : 47 64

Goodman, M.M. 1999. Broadening the genetic diversity in maize breeding by use of exotic germplasm. pp. 139-148. In: J.G. Coors, S. Pandey (Eds.), The genetic and exploitation of heterosis in crops.

Goodman, M.M. 2004. Developing temperate inbreds using tropical maize germplasm: Rationale, results, conclusions. Maydica, 49:209-219.

Goodman, M.M., F. Castillo, R.N. Holley. 1988. US maize germplasm:origin, limitations, and alternatives. In: Russell $\mathrm{N}$, Listman GM (eds) Recent advances in the conservation and utilization of genetic resources: Proc Global Maize Germplasm Workshop. CIMMYT, Mexico, DF, pp 130-148

Griffing, B. 1956. Concept of general and specific combining ability in relation to diallel crossing systems. Aust. J. Biol. Sci, 9:463-493.

Hallauer A.R., J.B. Miranda. 1988. Quantitative genetics in maize breeding. 2nd ed. Iowa State University Press. Ames, IA.
Hallauer, A.R., W.A Russel, K.R. Lamkey. 1988. Corn breeding. Pp. 469-564. In: G.F. Sprague, J.W. Dudley (eds), Corn and Corn Improvement. 3rd. Ed., ASA, CSSA and SSSA, Medison, WI, USA.

Hao, Z.F., X.H. Li, Z.J. Su, C.X. Xie, M.S. Li, X.L. Liang, J.F. Weng, D.G. Zhang, L. Li. S.H. Zhang. 2011. A proposed selection criterion for drought resistance across multiple environments in maize. Breeding Science, 61:101-108.

İlker, E., F.A. Tonk, O. Caylak, M. Tosun, I. Ozmen. 2009. Assessment $\mathrm{Of}$ genotype $\mathrm{X}$ environment interactions for grain yield in maize hybrids using ammi and gge biplot analyses. Turkish Journal of Field Crops, 14 (2): 123 - 135

Lan, J. 1998. Comparison of evaluating methods for agronomic drought resistance in crops. Acta Agriculturae Borealioccidentalis Sinica, 7: 85-87.

Messina, C., G. Hammer, Z. Dong, D. Podlich, M. Cooper. 2009. Modelling crop improvement in a GxExM framework via gene-trait-phenotype relationships. In: Sadras V, Calderini D, eds. Crop physiology: interfacing with genetic improvement and agronomy. Amsterdam, The Netherlands: Elsevier, 235-265

Mikel, M.A. 2006. Availability and analysis of proprietary dent corn inbred lines with Expired U.S. plant variety protection. Crop Science, 46:2555-2560.

Mikel, M.A., J.W. Dudley. 2006. Evolution of north American dent corn from public to proprietary germplasm. Crop Sci. 46: 1193-1205.

Nelson, P.T., N.D. Coles, J.B. Holland, D.B. Bubeck, S. Smith, M.M. Goodman. 2008. molecular characterization of maize inbreds with expired U.S. plant variety protection. Crop Sci. $48: 1673-1685$

Nelson, P.T., M.M. Goodman. 2008. Evaluation of elite exotic maize inbreds for use in temperate breeding. Crop Sci. 48:85-92.

Ribaut, J.M., C. Jiang, D. Gonzalez-De-Leon, G.O. Edmeades, and D.A. Hoisington. 1997. Identification of quantitative trait loci under drought conditions in tropical maize: I. yield components and marker-assisted selection strategies. Theor. Appl. Genet. 94:887- 896.

Russel, W.A. 1991. Genetic improvement of maize yields. Adv. Agron. 46:245-298

Smith, J.S.C. 1988. Diversity of United States hybrid maize germplasm; isozymic and chromatographic evidence. Crop Sci 28: 63-69

Tallury, S.P., M.M. Goodman. 1999. Experimental evaluation of the potential of tropical germplasm for temperate maize improvement. Theor Appl Genetics, 98: 54- 61

Tollenar, M. 2000. Genetic gain in corn hybrids from the northern and central Corn Belt. Proc. Annu. Corn \& Sorghum Res. Conf. 55:53-62.

Tollenar, M., J. Wu. 1999. Yield improvement in temperate maize is attributable to greater stress tolerance. Crop Science, 39: 1597-1604

UPOV, 2009. International Union For The Protection Of New Varieties Of Plants (UPOV). www.upov.int

Zhang, Y., M.S. Kang, K.R. Lamkey. 2005. DIALLEL-SAS05: A comprehensive program for Griffing's and GardnerEberhart analyses. Agron. J. 97:1097-1106

Ziyomo, C., R. Bernardo. 2012. Drought tolerance in maize: Indirect selection through secondary traits versus genome wide selection. Crop Science, 53:1269-1275. 